\title{
"Tobacco dependence treatment makes no sense because"...: Rebuttal of commonly-heard arguments against providing tobacco dependence treatment in the hospital setting
}

\author{
James Balmford ${ }^{1 *}$, Jens A Leifert ${ }^{2}$ and Andreas Jaehne ${ }^{1,3}$
}

\begin{abstract}
Background: The provision of tobacco dependence treatment in health care settings, particularly in countries lacking a history of strong tobacco control policy implementation, is limited by continued misconceptions on the part of health professionals and decision-makers regarding its worth and efficacy. In this paper, we rebut 9 arguments against the provision of tobacco dependence treatment that we have encountered in our experiences implementing and maintaining a dedicated smoking cessation service at a large university hospital in southern Germany.

Discussion: Broadly, the arguments relate to the nature of addiction, the efficacy and safety of stop-smoking medication and behavioural support, and the benefits and challenges of quitting. They include: (a) If smokers really want to quit, they will be able to do it alone (without help); (b) You can't forbid patients from doing what they want; (c) Patients will be upset if you talk to them about their smoking; (d) Stop-smoking medication has side effects that are more dangerous than smoking; (e) You have to be well trained to help smokers to quit (otherwise you can do more harm than good); (f) If you smoke yourself, you lack credibility; (g) If you have cancer, it is too late to quit; (h) Nicotine withdrawal is dangerous for heavy smokers; and (i) Smokers die earlier, thus reducing costs to the health system.
\end{abstract}

Summary: It is hoped that the counter-arguments presented here arm tobacco control advocates and practitioners working in health care settings, particularly in countries which have not prioritised tobacco control, to respond appropriately and convincingly to those opposed to the provision of tobacco dependence treatment.

Keywords: Tobacco dependence treatment, Hospital, Tobacco control

\section{Background}

More than 5 million people are estimated to die each year from smoking related diseases worldwide [1]; it has been conservatively estimated that smoking kills about one half of all persistent users [2]. Quitting smoking has immediate as well as long-term health benefits for men and women of all ages, reducing risks for diseases caused by smoking and improving health in general [3], including among those with chronic disease [4,5].

\footnotetext{
* Correspondence: James.Balmford@cancervic.org.au

${ }^{1}$ Präventionsteam (PT), Tumorzentrum Freiburg, Albert-Ludwigs-Universität Freiburg, Hugstetter Str. 55, 79106 Freiburg, Germany

Full list of author information is available at the end of the article
}

The health care system, including hospitals, is an important channel for delivering tobacco dependence treatment (TDT) to smokers. There is increasing recognition that treating tobacco use should be a high priority for health professionals and those who fund health care provision (e.g. [6]), and that all patients should be asked about tobacco use, advised to quit, and given appropriate assistance both during the hospital stay and postdischarge [6]. However, provision of TDT remains lower than optimal in many countries [7], including in Germany where we are located, where few hospitals provide structured cessation assistance to patients who smoke [8].

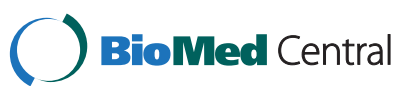

(c) 2014 Balmford et al.; licensee BioMed Central Ltd. This is an Open Access article distributed under the terms of the Creative Commons Attribution License (http://creativecommons.org/licenses/by/4.0), which permits unrestricted use, distribution, and reproduction in any medium, provided the original work is properly credited. The Creative Commons Public Domain Dedication waiver (http://creativecommons.org/publicdomain/zero/1.0/) applies to the data made available in this article, unless otherwise stated. 
Moreover, the role of health professionals in providing TDT in Germany is often disputed [9]. Resistance to the provision of TDT may largely stem from misperceptions about the safety and/or efficacy of established treatments, and a lack of understanding of the nature of addiction and how this perpetuates tobacco use [9]. A recent study of over 19,000 medical students in Germany found that over half believed that willpower alone was more effective than a combination of group therapy and nicotine replacement therapy [10].

In this paper, we discuss and rebut nine of the most common arguments we have encountered in implementing a dedicated tobacco dependence treatment service at a large university hospital in Freiburg (a medium-sized city in southern Germany), and in our efforts to implement similar services in other hospitals throughout the country over the past couple of years. Broadly, these misperceptions relate to the nature of addiction (3 arguments), the efficacy and safety of stop-smoking medication and behavioural support (3 arguments), and the benefits and challenges of quitting ( 2 arguments). The final argument relates to the worth of quitting for the health care system, and being more philosophical in nature, we dispute it both on philosophical and empirical grounds.

For many in Western countries that have made considerable progress in tobacco control, the issues presented and arguments raised may seem rather basic, even irrelevant. However, our audience is not advocates in these countries, but rather those from countries which have not prioritised TDT for whom these issues are likely to be highly relevant. We hope to prepare advocates of TDT in health care settings for some of the counter-arguments they may also encounter, and more broadly to draw attention to the continuing knowledge gaps that lead to their perpetuation.

\section{Discussion}

\section{Misperceptions related to the nature of addiction}

a. If smokers really want to quit, they will be able to do it alone (without help).

Perhaps the most remarkable observation about tobacco use is the fact that many smokers simply do not want to continue to smoke. An international cohort study of smokers found that about $90 \%$ regret ever having started to smoke [11], and a similar proportion report that they would like to quit if it were 'painless' to do so [12]. Quit attempts are common - it is estimated that on average smokers make one serious quit attempt per year [13], but most attempts are unaided [14], and only 3-5\% of unaided attempts are successful [15]. Older smokers [16,17] and those who are more nicotine dependent [18] are less likely to make quit attempts, less confident in their ability to succeed, and more likely to experience regret.

At the core of this belief is the perception that 'really wanting to quit' (i.e., high motivation) is both necessary and sufficient to be able to quit successfully. Seventy percent of smokers believe this to be the case [19]. However, while motivation to quit is a strong predictor of making a quit attempt, it is not predictive of success [20]. Indeed, some studies have found that smokers who are highly motivated to quit may even be less likely to succeed than those who are only moderately motivated $[21,22]$. There are a number of available forms of behavioral or pharmacological tobacco dependence treatment that may improve a smoker's chances of quit success. For example, a recent population-based study found that smokers are around four times more likely to succeed in quit attempts if they use stop-smoking medication, with one medication, varenicline, associated with a nearly sixfold increase in success [23]. Many smokers are either unaware of, or underestimate the benefit of, these effective forms of help [24].

b. You can't forbid patients from doing what they want.

People have a free choice to smoke, but free choice involves having adequate knowledge relevant to that choice (something that is central to the notion of informed consent). Health professionals, far from compromising their patients' free choice, are actually enhancing their capacity to exercise free choice by ensuring that they understand how continuing to smoke may affect their health [25]. While almost all smokers know that smoking is harmful to health, few have a realistic understanding of either the severity of smoking-caused disease or their personal susceptibility [26]. Moreover, it could be argued that because of the addictive nature of nicotine, many smokers are not actually 'doing what they want' in continuing to smoke. Rather, as we have seen, many are continuing to engage in a behaviour that they know is harmful and which they would like to give up $[11,12]$.

It is common for health professionals to recommend that patients modify their behavior when they believe such changes will be beneficial (for example, when patients are asked to reduce their weight). Providing patients with relevant information, and trying to motivate them to change their behaviour in ways that will benefit 
their health is consistent with providing quality health care.

\section{c. Patients will be upset if you talk to them about their smoking.}

Few smokers proactively seek personal assistance to stop smoking. It is estimated that only $1 \%$ of smokers access telephone support services (quitlines) annually [27], and even fewer seek face-to-face counseling [14]. Nonetheless, a far higher proportion of smokers are interested in smoking cessation advice and support if it is offered to them [28-32]. For example, when smokers were offered an Internet or mobile phone-based automated intervention without prior knowledge that this would occur, 60\% accepted the offer, and most of these went on to use the intervention sufficiently to obtain a probable therapeutic benefit [30]. In a primary care setting, simply informing smokers by letter that they could access a free consultation with a tobacco treatment specialist resulted in over $10 \%$ taking up the offer [31]. Finally, over $80 \%$ of patients referred to the smoking cessation service we established at the Universitätsklinikum Freiburg agreed to receive counseling when approached at bedside, and of these, over half (55\%) agreed to formulate a treatment plan including the receipt of post-discharge phone support [32].

When offered support in an empathic, respectful manner, it is possible to reach even those smokers who appear unmotivated to quit [33]. The principles of motivational interviewing [34] provide guidance on effective ways to understand smokers' attitudes and beliefs and to increase their motivation to quit.

Patients who smoke typically appreciate offers of cessation assistance, despite not always appearing to respond favourably. For example, in an intervention study conducted in a German hospital, two-thirds of cardiology patients offered brief smoking cessation counselling reported that the counselling was helpful, and $87 \%$ said that it was important to them. Interestingly, this contrasted markedly with qualitative reports of nurses' perceptions of the same interactions, which were that patients often felt uncomfortable and refused to be counselled [35]. Health professionals should be encouraged that their efforts to address their patients' smoking are likely to be well received.

2. Misperceptions related to the efficacy and safety of stop-smoking medication and behavioural support a. Stop-smoking medication has side effects that are more dangerous than smoking.
Nicotine replacement therapy (NRT), available over-the-counter in many countries, is designed to alleviate symptoms of nicotine withdrawal [36]. NRT does not mimic the effects of a cigarette, but delivers low-level doses of nicotine in a non-combustible form and at a slower rate, and as such has low abuse potential [37]. NRT does not contain the over 4000 other chemicals present in tobacco smoke, of which 69 are known carcinogens [38].

The safety and efficacy of NRT has been studied in clinical trials and real-world studies for over 30 years. A systematic review of clinical trials found that NRT is associated with minor adverse events, including insomnia (11.0\%) and gastrointestinal complaints (10.8\%), which may cause mild discomfort [39]. The most serious adverse event reported with notable frequency was heart palpitations/chest pains (3\%). Safety concerns have been expressed for people with pre-existing cardiovascular disease, but there is no evidence that NRT causes life-threatening complications (see also [40]), and the benefits of smoking cessation exceed any risk [41]. In addition, there is currently insufficient evidence for the safety or efficacy of NRT in pregnancy [42]. Other common side effects of NRT are associated with the mode and site of administration (e.g. 0 skin irritation where the nicotine patch is placed, or mouth ulcers following use of orallyadministered NRT). Such problems are generally mild and can be easily overcome by switching to a different form (e.g. from the patch to nicotine gum). Two forms of prescription-only medication for smoking cessation, bupropion and varenicline $[43,44]$, are associated with some additional safety concerns. Bupropion is associated with an increased risk of seizure, occurring in $0.1 \%$ of users [43], and is consequently contraindicated in smokers with a seizure disorder. A 2011 meta-analysis reported an association between varenicline use and increased cardiovascular events [45], leading the US Food and Drug Administration (FDA) to issue a warning that varenicline might increase the risk of cardiovascular events in patients with cardiovascular disease [46]. However, this review has been criticised for inappropriately excluding trials with no reported adverse events, among other methodological issues. A more recent review found no significant increase in serious cardiovascular adverse effects associated with varenicline use, either during treatment or for 30 days post-treatment [47]. 
Concerns have also arisen about the potential of bupropion and varenicline to exacerbate neuropsychiatric symptoms. A full discussion of this issue is beyond the scope of this article, but the FDA currently recommends that both medications be used with caution by individuals with a history of psychiatric illness [46].

b. You have to be well trained to help smokers to quit (otherwise you can do more harm than good).

Clinicians can do a number of things to encourage their patients to quit that do not require extensive training. At any given time, even though most smokers are not actively planning to quit, thoughts about quitting are common [13]. Thus, the task is often to encourage smokers to commit themselves to making the quit attempt that they are contemplating, rather than to convince them to do something they do not want to do.

Research has shown that even brief advice delivered by a physician (of as little as three minutes duration) can be effective compared to no advice, increasing quitting by $1-3 \%$, and effectiveness increases with greater duration [48]. While this may not seem to be a large difference, and it is easy to get discouraged by a perceived lack of success, motivation to quit can come from numerous sources (e.g. friends, family, policies designed to reduce tobacco use, and health professional advice). Each of these influences is likely to have a cumulative effect.

Clinicians can easily learn to administer very brief, effective advice and assistance by obtaining minimally intensive training [48]. However, those who do not feel confident about their ability to provide more extensive behavioral support, where patients need it, usually have a number of treatment options to which smokers can be referred. Behavioral support designed to enhance motivation and teach practical skills and strategies can be provided by telephone quitlines, qualified therapists or via new technologies such as the Internet or mobile phones. Simple referral mechanisms to these services are frequently available. Clinicians will benefit from familiarising themselves with reputable websites (www. quitcoach.org.au and www.smokefree.gov are good examples; high-quality German-language sites include www.bzga.de und www.tabakkontrolle.de), and the number of the local quitline.

c. If you smoke yourself, you lack credibility. First, it is important to acknowledge that this is a genuine issue. It is likely to be difficult for health professionals who smoke to convince patients to make lifestyle changes that they themselves are not making. Accordingly, primary care physicians who smoke are less likely to discuss smoking with their patients or to provide quitting assistance [49].

However, it is not hypocritical for a doctor who smokes to advise a patient that smoking can damage his or her health. Quitting smoking is unequivocally a good thing for the patient's current and future health, regardless of the smoking status of the person giving the advice. It is of course possible that some smokers will reject advice from a physician who smokes because they perceive him/her as lacking credibility. On the other hand, some may be more likely to accept advice from a physician who has personal experience of the difficulty of quitting. We know of no studies that have explored this, but clinical experience suggests that many smokers want to know whether the person advising them to quit has ever smoked.

\section{Misperceptions related to the benefits and challenges of quitting}

\section{a. If you have cancer, it is too late to quit.}

Cancer patients who quit smoking experience the many physical and psychological benefits of quitting that are common to all patients, outcomes that may contribute in turn to improved response to treatment. Continuing to smoke following a cancer diagnosis contributes to a number of adverse outcomes, including tumour progression, the development of a second primary cancer e.g. [50] and poorer survival rates following chemotherapy treatment e.g. [51]. Smoking is also known to negatively affect the ongoing quality of life of cancer patients [52,53]. Even in advanced lung cancer, quitting smoking is known to improve pulmonary function [54]. A cancer diagnosis is a major motivator for a quit attempt. Reviewing 11 studies that reported rates of abstinence after a cancer diagnosis, Cox et al. [55] found that across studies, 14-58\% of patients who smoked at the time of diagnosis continued to smoke after cancer treatment. This compares favourably to annual quit rates of 4-5\% in the general population of smokers [56], yet many cancer patients continue to smoke. At all stages in the cancer treatment process (diagnosis, during oncological treatment, post-treatment recovery), cancer patients are typically receptive to advice about quitting smoking and to participation in tobacco dependence treatment [55]. Cox et al. [55] stresses the need for interventions which are 
sensitive to the needs of cancer patients, both to promote initial abstinence and to prevent smoking relapse.

\section{b. Nicotine withdrawal is dangerous for heavy} smokers.

Common symptoms of nicotine withdrawal include cravings, irritability/anger/frustration, anxiety, depression, impaired concentration, insomnia and restlessness [36]. Many of these are common to a number of other drug withdrawal syndromes, not only to smoking cessation. While the time course of the individual symptoms tends to differ, nicotine withdrawal peaks on average within the first week of abstinence and lasts for 2-4 weeks.

It is difficult to know in what sense nicotine withdrawal is considered dangerous by those ascribing to this view. Certainly, impaired concentration or insomnia could lead to accidents, but we are unaware of any medical basis for the argument. In smokers with a mental health condition, e.g. depression, smoking cessation may require medical management due to required changes in medications affected by nicotine [57]. Nicotine replacement therapy can reduce the severity of withdrawal symptoms, easing physical discomfort and controlling urges to smoke [58]. Smokers who have had the experience of temporary withdrawal, e.g. during long-distance flights or when suffering from a cold and unable to smoke, have experience coping with these symptoms at least for a while. It should also be noted that the experience of severe withdrawal symptoms is not a given; many ex-smokers report that quitting smoking was easier than they expected [59].

To the extent that hospitals implement smoking restrictions, even patients who do not want to quit may experience some degree of nicotine withdrawal. For others, nicotine withdrawal may be a primary concern. The nicotine patch is considered the most appropriate form of NRT for hospitalized patients if they are experiencing nicotine withdrawal [60], because unlike oral forms it does not require repeated administration throughout the day. It has been recommended that patients who smoke more than 10 cigarettes per day should be provided with NRT if not contraindicated [61].

\section{Smokers die earlier, thus reducing costs to the} health system.

It is often argued that smokers actually save the health system money by dying early, thereby avoiding lengthy and expensive care in old age. One of the first studies to have explored whether this is true, published in the New England Journal of Medicine [62], found that because non-smokers live longer and incur greater costs of treating diseases unrelated to smoking, the initial savings on health care costs if all smokers quit would be reversed within 15 years. However, this study only considered a narrow range of smoking-related diseases, and is therefore likely to have greatly underestimated differences in health care utilization between smokers and non-smokers. A more recent Danish study [63] included a broader set of smoking-related diseases, and found substantial lifetime cost savings resulting from smoking cessation, particularly in those who quit at younger ages (e.g., $€ 24,800$ in total lifetime healthcare costs in a moderate smoker, male, who quits at age 35).

Studies which conclude that smoking has a net economic benefit to a society tend to be beset with methodological flaws, most notably (a) counting tobacco taxes as benefits of smoking, when they are nothing more than a transfer of resources already in the economy (i.e., the same benefit would accrue if taxes were levied on alternative goods and services); and (b) failure to conduct the appropriate comparison: the economy with tobacco versus the economy without tobacco [64]. Were smoking prevalence to reduce to $0 \%$, expenditure previously allocated to tobacco would simply be reallocated, with the resultant growth in other industries making up for (or adding to) any economic effect of reduced smoking. A full discussion of this and other economic arguments has been provided by Warner and Fulton [65].

Notwithstanding the economic benefit of reduced tobacco consumption, the notion that early, avoidable deaths should be considered a virtue is highly troubling from an ethical perspective, particularly when this argument is put forward by those who have a professional duty to prolong life. Each person who dies in middle age as a result of smoking is just that: a person; someone's mother or father, best friend, or valued work colleague. It is also fails to recognise the reality of long-term reduced quality of life that is characteristic of chronic smoking-related diseases such as emphysema (which naturally result in greatly increased health care expenditures during smokers' lives).

\section{Summary}

In this paper, we have presented 9 arguments which may be used to oppose the provision of tobacco dependence 
treatment in the hospital setting, typically in countries lacking a history of strong tobacco control policy and/or where the health care system has not prioritised tobacco treatment delivery. It is hoped that the counter-arguments presented here anticipate these concerns and provide advocates with ways to respond convincingly.

The importance of using the opportunity afforded by hospitalization to help smokers end their dependence on tobacco should not be underestimated. Hospitalization provides a unique opportunity to help smokers initiate a smoking cessation attempt, and receive the support they need to ensure that the attempt is successful. It is a potentially powerful 'teachable moment' in which smokers are often particularly motivated to quit and receptive to assistance due to concerns about their health [61]. We echo Fiore's [6] endorsement of the US Joint Commission's Tobacco Cessation Performance Measure-Set, which mandates participating hospitals to deliver evidencebased tobacco dependence counselling and medication for all admitted patients who use tobacco, and promote it as a model for implementation in other countries. Health care systems should also prioritise efforts to train health professionals in tobacco dependence treatment, so that brief counseling of smokers becomes part of their daily routine, and to increase awareness of the various forms of evidence-based treatment. Moreover, there is a need to provide accessible and effective smoking cessation assistance to health professionals who smoke themselves, so they do not undermine their status as communicators of health information and role models for healthy behaviour.

In addition, we have argued that the majority of hospitalised smokers, despite possible ambivalence toward stopping smoking, will nonetheless be receptive to (and often grateful for) the offer of non-judgmental assistance to quit. It is common for health professionals to feel illequipped to provide such assistance, but even very brief advice can have a positive impact. Where more intensive help is desired, a number of safe and effective stopsmoking medications exist, as well as a range of behavioural treatment options. We caution, however, that discharged patients will rarely actively make contact with cessation services to which they have been referred [66]. For this reason, if contact with a face-to-face or telephone service is recommended, it is likely to always be preferable for the service to initiate contact with the patient (where possible). In countries where telephone counselling is widely available, hospitals and quitlines can work collaboratively to ensure that post-discharge support is provided proactively to smokers [67].

Finally, we have argued against the presumption that if smokers really want to quit, they will be able to do so without help. High motivation to quit smoking does not inevitably lead to success. However, this is not the same as arguing that smokers are unable to quit without help. Indeed, most successful ex-smokers report having quit unassisted; it is by far the most widely-used strategy [59]. We recommend that health professionals respect their patients' wishes if they prefer to try to quit without formal help, but to monitor their progress, normalise difficulties, and be ready to discuss treatment options if unassisted attempts fail.

\section{Abbreviations}

TDT: Tobacco dependence treatment; NRT: Nicotine replacement therapy; FDA: Food and Drug Administration.

\section{Competing interests}

The smoking cessation service referred to in this article was originally funded by a Pfizer Global Public Health Partnership award, awarded to AJ, JL and colleagues.

\section{Authors' contributions}

$J B$ conceived of the idea for the manuscript and drafted the content. $J$ and AJ contributed arguments they have encountered in their clinical work and to the drafting of the manuscript. All authors have read and approved the final manuscript.

\section{Acknowledgements}

JB and AJ were supported by the Tumorzentrum Ludwig Heilmeyer, Universitätsklinikum Freiburg during the drafting of this manuscript.

\section{Author details}

${ }^{1}$ Präventionsteam (PT), Tumorzentrum Freiburg, Albert-Ludwigs-Universität Freiburg, Hugstetter Str. 55, 79106 Freiburg, Germany. ${ }^{2}$ Department of Internal Medicine, Breisgauklinik, Bad Krozingen, Germany. ${ }^{3}$ Department of Psychiatry \& Psychotherapy, Universitätsklinikum Freiburg, Freiburg, Germany.

Received: 5 February 2014 Accepted: 15 September 2014

Published: 19 November 2014

\section{References}

1. World Health Organization: WHO Report on the Global Tobacco Epidemic. Geneva: World Health Organization; 2008.

2. Doll R, Peto R, Boreham J, Sutherland I: Mortality in relation to smoking: 50 years' observations on male British doctors. Br Med J 2004, 328:1519.

3. U.S. Department of Health and Human Services: The Health Consequences of Smoking: A Report of the Surgeon General. Atlanta, GA, US: Department of Health and Human Services, Centers for Disease Control and Prevention, National Center for Chronic Disease Prevention and Health Promotion; 2004. Office of Smoking and Health.

4. Anthonisen NR, Skeans MA, Wise RA, Manfreda J, Kanner RE, Connett JE: The effects of a smoking cessation intervention on 14.5 year mortality: a randomized clinical trial. Ann Intern Med 2005, 142:233-239.

5. Van Domburg RT, Op Reimer WS, Hoeks SE, Kappetein AP, Bogers AJ: Three life-years gained from smoking cessation after coronary artery bypass surgery: a 30-year follow-up study. Am Heart J 2008, 156:473-476.

6. Fiore MC, Goplerud E, Schroeder SA: The Joint Commission's new tobacco-cessation measures: will hospitals do the right thing? N Engl J Med 2012, 10:1056.

7. Kotseva K, Wood D, De Backer G, Pyorala K, Keil U: EUROPASPIRE III: a survey on the lifestyle, risk factors and use of cardioprotective drug therapies in coronary patients from 22 European countries. Eur J Cardiovasc Prev Rehabil 2009, 16:121-137.

8. Rupp A, Neudert M, Hetzel M: Smoking cessation programmes at hospitals with departments for lung diseases. Dtsch Med Wochenschr 2010, 135:501-506.

9. Raupach T, Merker J, Hasenfuß G, Andreas S, Pipe A: Knowledge gaps about smoking cessation in hospitalized patients and their doctors. Eur J Cardiovasc Prev Rehabil 2011, 18:334-341.

10. Raupach T, Strobel L, Beard E, Krampe H, Anders S, West R: German medical students' beliefs about the effectiveness of different methods of stopping smoking. Nicotine Tob Res 2013, 15:1892-1901. 
11. Fong GT, Hammond D, Laux FL, Zanna MP, Cummings KM, Borland R, Ross $\mathrm{H}$ : The near-universal experience of regret among smokers in four countries: findings from the International Tobacco Control Policy Evaluation Survey. Nicotine Tob Res 2004, 6(Suppl 3):S341-S351.

12. Mullins R, Borland R: Do smokers want to quit? Aust N Z J Public Health 1996, 20:426-427.

13. Borland $\mathrm{R}$, Partos TR, Yong H-H, Cummings KM, Hyland A: How much unsuccessful quitting activity is going on among adult smokers? Data from the International tobacco control four country cohort survey. Addiction 2012, 107:673-682.

14. Zhu S, Melcer T, Sun J, Rosbrook B, Pierce JP: Smoking cessation with and without assistance: a population-based analysis. Am J Prev Med 2000, 18:305-311.

15. Hughes JR, Keely J, Naud S: Shape of the relapse curve and long-term abstinence among untreated smokers. Addiction 2004, 99:29-38.

16. Messer K, Trinidad DR, Al-Delaimy WK, Pierce JP: Smoking cessation rates in the United States: a comparison of young adult and older smokers. Am J Public Health 2008, 98:317-322.

17. Yong $H-H$, Borland $\mathrm{R}$, Siahpush $\mathrm{M}$ : Quitting-related beliefs, intentions, and motivations of older smokers in four countries: findings from the International Tobacco Control Policy Evaluation Survey. Addict Behav 2005, 30:777-788.

18. Hyland A, Borland R, Li Q, Yong H-H, McNeill A, Fong GT, O'Connor RJ, Cummings KM: Individual-level predictors of cessation behaviours among participants in the International Tobacco Control (ITC) Four Country Survey. Tob Control 2006, 15:iii83-iii94.

19. Balmford J, Borland R: What does it mean to want to quit? Drug Alcohol Rev 2008, 2008(27):21-27.

20. Vangeli E, Stapleton J, Smit ES, Borland R, West R: Predictors of attempts to stop smoking and their success in adult general population samples: a systematic review. Addiction 2011, 106:2110-2121.

21. Borland R, Yong H-H, Balmford J, Cooper J, Cummings KM, O'Connor RJ, McNeill A, Zanna MP, Fong GT: Motivational factors predict quit attempts but not maintenance of smoking cessation: findings from the International Tobacco Control Four Country project. Nicotine Tob Res 2010, 12(Suppl 1):S4-S11.

22. West $R$, McEwen A, Bolling $K$, Owen L: Smoking cessation and smoking patterns in the general population: a 1-year follow-up. Addiction 2001 96:891-902

23. Kasza KA, Hyland AJ, Borland R, McNeill AD, Bansal-Travers M, Fix BV Hammond D, Fong GR, Cummings KM: Effectiveness of stop-smoking medications: findings from the International Tobacco Control (ITC) Four Country Survey. Addiction 2013, 108:193-202.

24. Hammond D, McDonald PW, Fong GT, Borland R: Do smokers know how to quit? Knowledge and perceived effectiveness of cessation assistance as predictors of cessation behaviour. Addiction 2004, 99:1042-1048.

25. Borland R, Li L, Driezen P, Wilson N, Hammond D, Thompson ME, Fong GT Mons U, Willemsen MC, McNeill A, Thrasher JF, Cummings KM: Cessation assistance reported by smokers in 15 countries participating in the International Tobacco Control (ITC) policy evaluation surveys. Addiction 2012, 107:197-205.

26. Chapman S, Liberman J: Ensuring smokers are adequately informed: reflections on consumer rights, manufacturer responsibilities, and policy implications. Tob Control 2005, 14(Suppl II):ii8-ii13.

27. Cummins SE, Bailey L, Campbell S, Koon-Kirby C, Zhu S-H: Tobacco cessation quitlines in North America: a descriptive study. Tob Control 2007, 16(Suppl I):i9-i15.

28. Murray RL, Coleman T, Antoniak M, Stocks J, Fergus A, Britton J, Lewis SA: The effect of proactively identifying smokers and offering smoking cessation support in primary care populations: a cluster-randomized trial. Addiction 2008, 103:998-1006.

29. Tzelepis F, Paul CL, Walsh RA, Wiggers J, Duncan SL, Knight J: Active telephone recruitment to quitline services: are nonvolunteer smokers receptive to cessation support? Nicotine Tob Res 2009, 11:1205-1215.

30. Balmford J, Borland R, Benda P, Howard S: Factors associated with use of automated smoking cessation interventions: findings from the eQuit study. Health Educ Res 2013, 28:288-299.

31. Rigotti NA, Bitton A, Kelley JK, Hoeppner BB, Levy DE, Mort E: Offering population-based tobacco treatment in a healthcare setting: a randomized controlled trial. Am J Prev Med 2011, 41:498-503.
32. Balmford J, Leifert JA, Schulz C, Elze M, Jaehne A: Implementation and effectiveness of a hospital smoking cessation service in Germany. Patient Educ Couns 2014, 94:103-109.

33. Pisinger C, Vestbo J, Borch-Johnsen $\mathrm{K}$, Jorgensen $\mathrm{T}$ : It is possible to help smokers in early motivational stages to quit: the Inter99 study. Prev Med 2005, 40:278-284.

34. Lai DTC, Cahill K, Qin Y, Tang JL: Motivational interviewing for smoking cessation (Review). Cochrane Database Syst Rev 2010, 1:CD006936.

35. Raupach T, Falk J, Vangeli E, Schiekirka S, Rustler C, Grassi MC, Pipe A, West $\mathrm{R}$ : Structured smoking cessation training for health professionals on cardiology wards: a prospective study. Eur J Prev Cardiol 2012, 21(7):915-922.

36. Hughes JR: Effects of abstinence from tobacco: valid symptoms and time course. Nicotine Tob Res 2007, 9:315-327.

37. West R, Hajek P, Foulds J, Nilsson F, Burrows S, Meadows A: A comparison of the abuse liability and dependence potential of nicotine patch, gum, spray and inhaler. Psychopharmacology (Berl) 2000, 149:198-202.

38. International Agency for Research on Cancer: Tobacco smoke and involuntary smoking. In IARC Monographs on the Evaluation of the Carcinogenic Risk of Chemicals to Humans, Volume 83. Lyon: International Agency for Research on Cancer; 2004.

39. Mills EJ, Wu P, Lockhart I, Wilson K, Ebbert JO: Adverse events associated with nicotine replacement therapy (NRT) for smoking cessation: a systematic review and meta-analysis of one hundred and twenty studies involving 177,390 individuals. Tob Induc Dis 2010, 8:8.

40. Hubbard R, Lewis S, Smith C, Godfrey C, Smeeth L, Farrington P, Britton J: Use of nicotine replacement therapy and the risk of acute myocardial infarction and death. Tob Control 2005, 14:416-421.

41. Joseph AM, Fu SS: Safety issues in pharmacotherapy for smoking in patients with cardiovascular disease. Prog Cardiovasc Dis 2003, 45:429-441.

42. Coleman T, Chamberlain C, Cooper S, Leonardi-Bee J: Efficacy and safety of nicotine replacement therapy for smoking cessation in pregnancy: systematic review and meta-analysis. Addiction 2011, 106:52-61.

43. Hughes JR, Stead LF, Lancaster T: Antidepressants for smoking cessation. Cochrane Database Syst Rev 2007, 1:CD000031.

44. Cahill K, Stead LF, Lancaster T: Nicotine receptor partial agonists for smoking cessation. Cochrane Database Syst Rev 2012, 4:CD006103.

45. Singh S, Loke YK, Spangler JG, Furberg CD: Risk of serious adverse cardiovascular events associated with varenicline: a systematic review and meta-analysis. Can Med Assoc J 2011, 183:1359-1366.

46. Food and Drug Administration: Public Health Advisory: FDA Requires New Boxed Warnings for the Smoking Cessation Drugs Chantix and Zyban. http:// www.fda.gov/Drugs/DrugSafety/PostmarketDrugSafetylnformationfor PatientsandProviders/DrugSafetyInformationforHeathcareProfessionals/ ucm 169986.htm. Accessed 18 December 2012

47. Prochaska JJ, Hilton JF: Risk of cardiovascular serious adverse events associated with varenicline use for tobacco cessation: systematic review and meta-analysis. Br Med J 2012, 344:e2856.

48. Fiore MC, Jaen CR, Baker TB, Bailey WC, Benowitz NL, Curry SJ, Dorfman SF, Froelicher ES, Goldstein MG, Healton CG, Henderson PN, Heyman RB, Koh HK, Kottke TE, Lando HA, Mecklenburg RE, Mermelstein RJ, Mullen PD, Orleans $C T$, Robinson L, Stitzer ML, Tommasello AC, Villejo L, Wewers ME: Treating tobacco use and dependence: 2008 update. In US Department of Health and Human Services 2008, Public Health Service.

49. Pipe A, Sorensen M, Reid R: Physician smoking status, attitudes toward smoking, and cessation advice to patients: an international survey. Patient Educ Couns 2009, 74:118-123.

50. Kawahara M, Ushijima S, Kamimori T, Kodama N, Ogawara M, Matsui K, Masuda N, Takada M, Sobue T, Furuse K: Second primary tumors in more than 2-year disease-free survivors of small-cell lung cancer in Japan: the role of smoking cessation. Br J Cancer 1998, 78:409-412.

51. Videtic GMM, Stitt LW, Dar AR, Kocha WI, Tomiak AT, Truong PT, Vincent $M D, Y u E W$ : Continued cigarette smoking by patients receiving concurrent chemoradiotherapy for limited-stage small-cell lung cancer is associated with decreased survival. J Clin Oncol 2003, 21:1544-1549.

52. Jensen $K$, Jensen $A B$, Grau C: Smoking has a negative impact upon health related quality of life after treatment for head and neck cancer. Oral Oncol 2007, 43:187-192.

53. Chen J, Qi Y, Wampfler JA, Jatoi A, Garces Yl, Busta AJ, Mandrekar SJ, Yang $P$ : Effect of cigarette smoking on quality of life in small cell lung cancer patients. Eur J Cancer 2012, 48:1593-1601 
54. Okubo K, Mark EJ, Flieder D, Wain JC, Wright CD, Moncure AC, Grillo HC, Mathisen DJ: Bronchoalveolar carcinoma: clinical, radiologic, and pathologic factors and survival. J Thorac Cardiovasc Surg 1999, 118:702-709.

55. Cox LS, Africano NL, Tercyak KP, Taylor KL: Nicotine dependence treatment for patients with cancer: Review and recommendations. Cancer 2003, 98:632-644.

56. Levy DT, Graham AL, Mabry PL, Abrams DB, Orleans CT: Modeling the impact of smoking cessation treatment policies on quit rates. Am J Prev Med 2010, 38(3 Suppl):S364-S372.

57. Zevin S, Benowitz NL: Drug interactions with tobacco smoking: an update. Clin Pharmacokinet 1999, 36:425-438.

58. Rigotti NA: Strategies to help a smoker who is struggling to quit. J Am Med Assoc 2012, 308:1573-1580.

59. Chapman S, Mackenzie R: The global research neglect of unassisted smoking cessation: causes and consequences. PLOS Med 2010, 7(2):e1000216.

60. Wolfenden L, Campbell E, Walsh RA, Wiggers J: Smoking cessation interventions for in-patients: a selective review with recommendations for hospital-based health professionals. Drug Alcohol Rev 2003, 22:437-452.

61. Rigotti N, Clair C, Munafò MR, Stead LF: Interventions for smoking cessation in hospitalised patients. Cochrane Database Syst Rev 2012, 5:CD001837.

62. Barendregt JJ, Bonneux L, Van der Maas PJ: The health care costs of smoking. N Engl J Med 1997, 337:1052-1057.

63. Rasmussen SR, Prescott E, Sorensen TIA, Sogaard J: The total lifetime health cost savings of smoking cessation to society. Eur J Public Health 2005, 15:601-606.

64. Ross H: Critique of the Philip Morris study of the cost of smoking in the Czech Republic. Nicotine Tob Res 2004, 6:181-189.

65. Warner K, Fulton G: Importance of tobacco to a country's economy: an appraisal of the tobacco industry's economic argument. Tob Control 1995, 4:180-183.

66. Lewis KE, Durgan L, Edwards VM, Dixon H, Whitehead C, Sykes RN: Can smokers switch from a hospital-based to a community-based stop smoking service? An open-label, randomized trial comparing three referral schemes. Nicotine Tob Res 2009, 11:756-764.

67. Cummins S, Zhu SH, Garnst A, Kirby C, Brandstein K, Klonoff-Cohen H, Chaplin E, Morris T, Seymann J, Lee J: Nicotine patches and quitline counseling to help hospitalized smokers stay quit: study protocol for a randomized controlled trial. Trials 2012, 13:128.

doi:10.1186/1471-2458-14-1182

Cite this article as: Balmford et al:: "Tobacco dependence treatment makes no sense because"...: Rebuttal of commonly-heard arguments against providing tobacco dependence treatment in the hospital setting. BMC Public Health 2014 14:1182.

\section{Submit your next manuscript to BioMed Central and take full advantage of:}

- Convenient online submission

- Thorough peer review

- No space constraints or color figure charges

- Immediate publication on acceptance

- Inclusion in PubMed, CAS, Scopus and Google Scholar

- Research which is freely available for redistribution 